\title{
The Success Rate of Endotracheal Intubation in the Emergency Department of Tertiary Care Hospital in Ethiopia, One-Year Retrospective Study
}

\author{
Ayalew Zewdie (iD, ${ }^{1}$ Dejene Tagesse, ${ }^{2}$ Selam Alemayehu, ${ }^{3}$ Tesfaye Getachew, ${ }^{1}$ \\ and Menbeu Sultan ${ }^{1}$ \\ ${ }^{1}$ Department of Emergency Medicine and Critical Care, St. Paul's Hospital Millennium Medical College, Addis Ababa, Ethiopia \\ ${ }^{2}$ Addis Ababa Burn Emergency and Trauma (AaBET) Hospital, Addis Ababa, Ethiopia \\ ${ }^{3}$ Department of Psychiatry, St. Paul's Hospital Millennium Medical College, Addis Ababa, Ethiopia
}

Correspondence should be addressed to Ayalew Zewdie; ayalew.zewdie@gmail.com

Received 28 June 2020; Revised 7 February 2021; Accepted 7 March 2021; Published 20 March 2021

Academic Editor: Edward A. Panacek

Copyright ( $\odot 2021$ Ayalew Zewdie et al. This is an open access article distributed under the Creative Commons Attribution License, which permits unrestricted use, distribution, and reproduction in any medium, provided the original work is properly cited.

Background. Emergency medical care starts with airway assessment and intervention management. Endotracheal intubation is the definitive airway management in the emergency department (ED) for patients requiring a definitive airway. Successful first pass is recommended as the main objective of emergency intubation. There exists no published research regarding the success rates or complications that occur within Ethiopian hospitals emergency department intubation practice. Objective. This study aimed to assess the success rate of emergency intubations in a tertiary hospital, Addis Ababa, Ethiopia. Methodology. This was a single institute retrospective documentation review on intubated patients from November 2017 to November 2018 in the emergency department of Addis Ababa Burn Emergency and Trauma Hospital. All intubations during the study period were included. Data were collected by trained data collectors from an intubation documentation sheet. Result. Of 15,933 patients seen in the department, $256(1.6 \%)$ patients were intubated. Of these, $194(74.9 \%)$ were male, $123(47.5 \%)$ sustained trauma, $65(25.1 \%)$ were medical cases, and 13(5\%) had poisoning. The primary indications for intubation were for airway protection (160 (61.8\%)), followed by respiratory failure $(72(27.8 \%))$. One hundred and twenty-nine $(49.8 \%)$ had sedative-only intubation, $110(42.5 \%)$ had rapid sequence intubation, and $16(6.2 \%)$ had intubation without medication. The first-pass success rate in this sample was $70.3 \%$ (180/256), second-pass $21.4 \%$ (55/256), and third-pass 7.4\% (19/256), while the overall success rate was 99.2\% (254/256). Hypoxia was the most common complication. Conclusion. The intubation first-pass success rate was lower than existing studies, but the overall intubation success rate was satisfactory.

\section{Background}

Emergency medical care starts with airway assessment and intervention management. Endotracheal intubation is the definitive airway management in the emergency department (ED) for patients requiring a definitive airway. Anesthetists and or emergency physicians (EPs) perfume intubations with or without drugs [1]. Advanced airway management is a basic skill that every emergency physician (EP) should acquire worldwide [2].
The most widely used emergency airway management is rapid sequence administration of sedation and paralytic agent with tracheal intubation (rapid sequence intubation (RSI)) [3]. RSI performed in critically ill and injured patients in the emergency room has a high risk of failed intubation and other complications than that in the operating room $[4,5]$. This is caused by several factors such as patients having significant comorbidities; they have not fasted and need to immobilize the cervical spine. In addition, clinical condition of the patient, the experience and training of the 
clinician, the urgency of the procedure, and the availability of equipment and personnel to support the procedure in the emergency room affect the success and complication of emergency intubation $[2,3]$.

Audit of critical emergency procedures helps to improve training, policy, and clinical practice development. In North America, surveillance studies demonstrated that ED intubations by emergency medicine residents and physicians, largely using a rapid sequence intubation technique, can be performed safely and with high levels of success [6].

A successful first pass is recommended as the main objective of emergency intubation. Study from the anesthesia literature showed that repeated attempt of intubations leads to a higher complication rate [7]. There are limited data from emergency medicine in the developing world about the success of airway management in the emergency room [8]. There is a need to fill this knowledge gap in order to identify the frequency of failed intubation and its causation so that clinical outcomes can be improved.

The aim of this study was to assess the success rate of emergency intubations in the tertiary hospital, Addis Ababa, Ethiopia.

\section{Methodology}

This was a single institute retrospective documentation review on intubated patients from November 2017 until November 2018 in the ED of Addis Ababa Burn Emergency and Trauma Hospital (AaBET Hospital), a major trauma centre in Addis Ababa, which is one of the biggest teaching hospitals in Ethiopia. AaBET currently provides health care services in several specialties: orthopaedics, neurosurgery, plastic and reconstructive surgery, emergency and critical care, and general surgery. AaBET hospital had approximately 20-30,000 annual emergency room visits. It provides outpatient services as well as elective and emergency surgeries.

The emergency medicine and critical care residency program, which is a 3-year program, was started in 2015. Residents were given an induction course on emergency medicine and critical care basic topics and practical skills before they start the clinical activity. Likewise, they underwent an airway course and had practical training on manikins. The study included intubations performed with or without the use of drugs. Patients who came intubated from other hospitals were excluded.

2.1. Operational Definitions. "An episode of intubation was defined as the process of intubation for each patient, whereas an attempt at intubation was defined as a single passage of the laryngoscope blade past the lips" [2].

"Difficult laryngoscopy was defined as Cormack and Lehane grade III or IV [2] and difficult intubation as one that requires more than two attempts. "Complications of orotracheal intubations were defined as peripheral oxygen saturation $\left(\mathrm{SpO}_{2}\right)<93 \%$, even if the patient was hypoxic before intubation and had bradycardia $<60 / \mathrm{min}$, hypotension requiring support, airway trauma, esophageal or main stem bronchial intubation, laryngospasm, cardiac arrest, or the performance of a surgical airway" [2].

2.2. Data Collection. All intubations in the ED were documented by ED nurse using a purpose designed documentation sheet (Annex-1) as close to the time of intubation as possible. The provider who intubated the patient signed the form after data were filled by the nurse. The documentation form was used by the staff during intubation as a standard protocol of the hospital.

We developed another form (Annex-2) for our analysis which includes age, sex, diagnosis, indication for intubation, anesthetic agents used for intubation, pre- and postintubation vital signs $(\mathrm{V} / \mathrm{s})$, immediate complications, and the number of intubation attempts, the intubation personnel, and outcome of intubation.

2.3. Statistical Analysis. Intubation data between November 2017 and November 2018 for one year were analyzed using SPSS version 21.

Descriptive statistics were performed on months of age, sex, diagnosis on admission, indication for intubation, number of patients in whom intubation was attempted, and number of attempts. The study was reviewed and approved by the hospital, Emergency Medicine Department Institutional Review Board.

\section{Results}

Out of 15,933 patients, a total of 256 intubations (1.6\%) were performed in the study period (Figure 1). One hundred ninety-four $(75.8 \%)$ of the intubated patients were male, and $62(23.9 \%)$ were female. The median age was 30 years with an interquartile range of 20 and 49 (Table 1).

3.1. Diagnosis and Indication for Intubation. One hundred twenty-three patients (48.0\%) sustained trauma (Figure 2).

The primary indications for intubation were for airway protection 160 (62.5\%), followed by respiratory failure 72 (28.1\%). An indication for the remainder was not documented.

3.2. Type of Intubation. The types of intubation used were as follows: 129 (50.3\%) sedative-only intubation, 110 (42.9\%) rapid sequence intubation, 16 (6.3\%) intubation without medication. The most common induction agent used was ketamine, and the only paralytic agent was succinylcholine (Table 2).

First-year residents used RSI in 56 (50.9\%) patients, sedation only intubation in $58(45.0 \%)$, and intubation without medication in $5(31.3 \%)$ patients during first attempt of intubation (Figure 3).

3.3. Attempt and Success Rate. The first-pass success rate in this sample was $70.3 \%(180 / 256)$, second-pass $21.4 \%(55 /$ 256), and third-pass 7.4\% [9], while the overall success rate was $99.2 \%$ (254/256). There were only two failed intubations in the one-year period after trial of RSI that required 


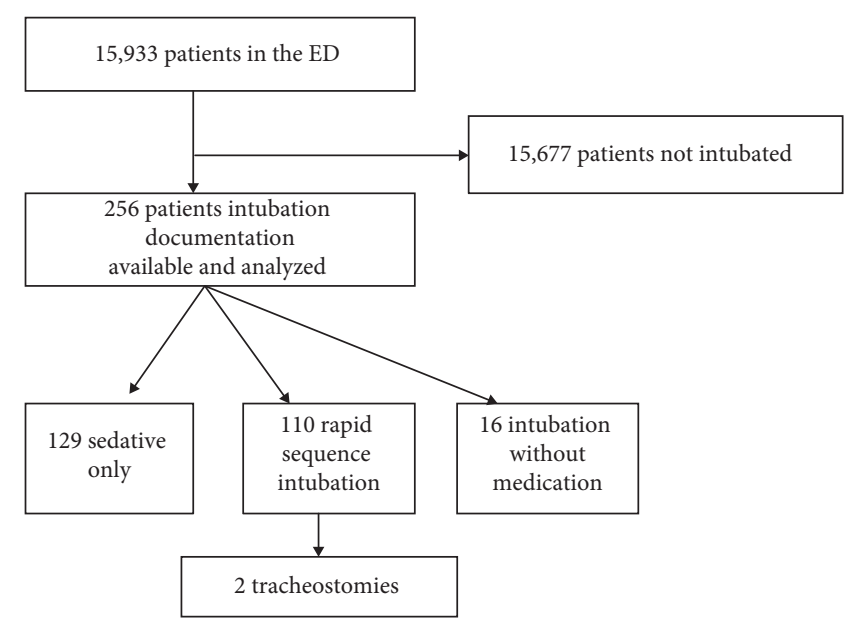

FIGURE 1: Flow chart showing data analysis of emergency intubations.

Table 1: Demographics and frequency of intubations at Addis Ababa, Ethiopia.

\begin{tabular}{|c|c|c|}
\hline Variables & Subclass & Frequency and percentage $(N=256), n(\%)$ \\
\hline \multirow{3}{*}{ Age } & $<18$ & $37(14.5)$ \\
\hline & $\geq 18$ & $196(76.5)$ \\
\hline & Missing & $23(9.0)$ \\
\hline \multirow{2}{*}{ Sex } & Male & $194(75.8)$ \\
\hline & Female & $62(24.2)$ \\
\hline \multirow{4}{*}{ Preintubation GCS } & $3-8$ & $111(43.4)$ \\
\hline & $9-12$ & $25(9.8)$ \\
\hline & $13-15$ & $43(16.8)$ \\
\hline & Missing & $80(30.0)$ \\
\hline \multirow{5}{*}{ Preintubation SBP } & $<90$ & $17(6.6)$ \\
\hline & $90-120$ & $73(28.5)$ \\
\hline & $120-160$ & $119(46.5)$ \\
\hline & $>160$ & $27(10.5)$ \\
\hline & Missing & $23(8.9)$ \\
\hline \multirow{5}{*}{ Preintubation PR } & $<60$ & $23(8.9)$ \\
\hline & $60-100$ & $89(34.8)$ \\
\hline & $101-150$ & $110(43.0)$ \\
\hline & $>150$ & $17(6.6)$ \\
\hline & Missing & $17(6.6)$ \\
\hline \multirow{5}{*}{ Preintubation RR } & $<12$ & $1(0.4)$ \\
\hline & $12-24$ & $69(26.9)$ \\
\hline & $24-35$ & $56(21.8)$ \\
\hline & $>35$ & $44(17.1)$ \\
\hline & Missing & $86(33.8)$ \\
\hline \multirow{3}{*}{ Preintubation $\mathrm{SpO}_{2}$} & $<90$ & $73(28.5)$ \\
\hline & $\geq 90$ & $172(67.2)$ \\
\hline & Missing & $11(4.3)$ \\
\hline
\end{tabular}

Index. PR, pulse rate; SBP, systolic blood pressure; RR, respiratory rate; GCS, Glasgow Coma Scale.

emergency tracheostomy for the diagnosis of tracheal stenosis, and they were performed by surgeons.

From 254 successful intubations, 122 (48.0\%), 66 (25.9\%), $34(13.3 \%)$, and $32(12.5 \%)$ were intubated by second-year residents, first-year residents, consultants, and third-year residents, respectively (Table 3 ).
3.4. Complications of Intubation. The overall complication rate was $28.5 \%(73 / 256)$. Thirty-two patients had hypoxia with $\mathrm{SpO}_{2}<93 \%$, and 25 had hypotension (Table 4).

Type of intubation versus demographics, level of intubators, final success of intubation, and complication is shown in Table 5. 


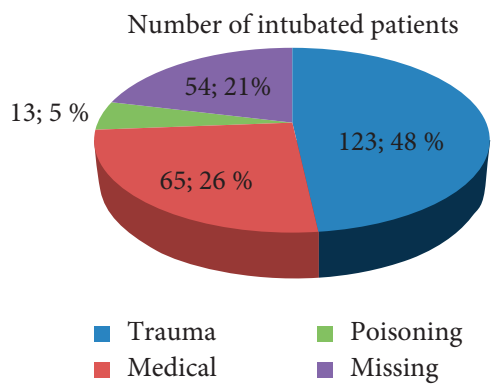

FIgUre 2: Indications of intubated patients of AaBET hospital Addis Ababa, Ethiopia.

TABle 2: Medications used during intubations at Addis Ababa, Ethiopia.

\begin{tabular}{lcccc}
\hline Medication class & Name of medication & RSI, $n=110(\%)$ & SED, $n=129(\%)$ & Frequency $(N=256)(\%)$ \\
\hline & Ketamine & $98(89.1)$ & $84(65.1)$ & $182(71.1)$ \\
Induction/sedative & Ketamine with diazepam & $3(2.7)$ & $22(17.1)$ & $25(9.8)$ \\
& Propofol & $4(3.6)$ & $14(10.8)$ & $18(7.0)$ \\
Paralytics & Thiopental & $4(3.6)$ & $4(3.1)$ & $8(3.1)$ \\
\hline
\end{tabular}

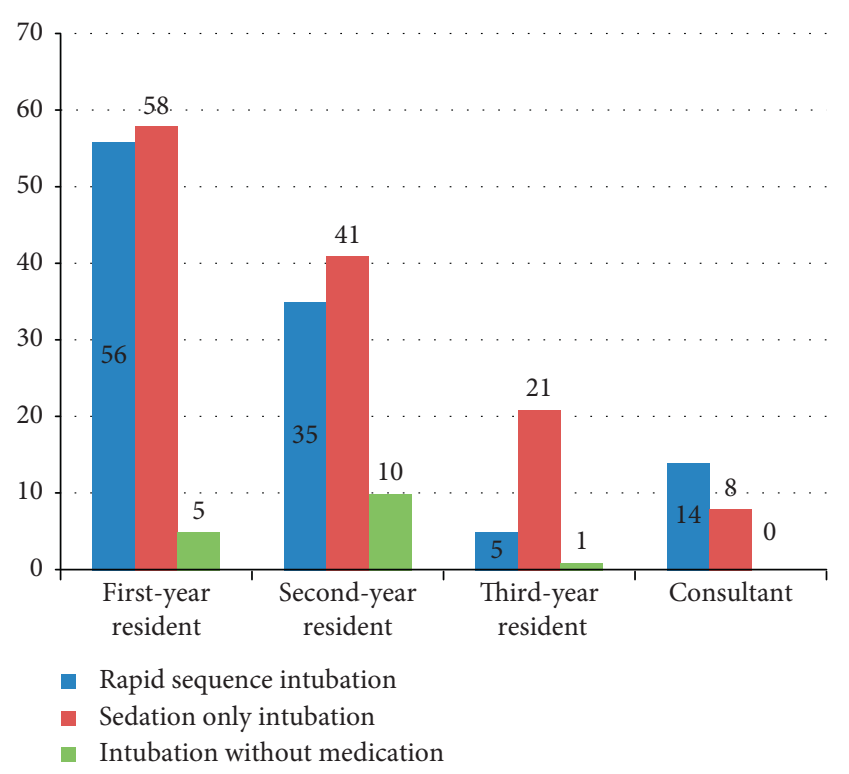

FIgUre 3: Level of intubators and type of intubations at AaBET hospital, Addis Ababa, Ethiopia.

\section{Discussion}

This was the first descriptive study on intubation in the emergency department of AaBET hospital.

In the finding of this study, all ED intubations were managed by emergency residents and physicians. This was not the case in other countries $[2,10]$.

Our study demonstrated poor success rates for first-year residents on the initial attempt related to the other senior residents. On the contrary, the success rate of $70.3 \%$ on the first attempt was not satisfactory and lower than that of studies from other countries, in which the success rate ranged from $80 \%$ to $90 \%[2,11-14]$. Besides, the majority of the intubated patients had trauma, which could increase the difficulty in intubation and necessitates further training and practice. Lastly, all intubations were done by direct laryngoscope because there was no video laryngoscope in the hospital which could have improved first-pass success [15]. The first-attempt success rate was higher than reports from Japan on intubated trauma patients, where the overall first attempt success rate was $63.8 \%$ [16].

The most common indications for intubation were airway protection (61.8\%), followed by respiratory failure. This could be because most of the intubated patients were trauma patients $(123 / 256)$.

Also of note, intubation with sedation (129/256) was somewhat more frequent higher than rapid sequence intubation $(110 / 256)$ in this study. Most studies recommend RSI in the emergency room instead [6, 17, 18]. In our opinion, this may be because most patients had trauma requiring airway protection anticipating possible difficulty in intubation or because of fear of paralytic drug complication likely implying a lack of confidence in the ability to deal with prolonged apnea. In this study, even though firstyear residents used RSI for intubation more frequently than senior residents, the first-year success rate was poor, which suggests, as would be expected, that experience is more important than the type of intubation. However, further study is needed for why intubation with sedation is used more by intubators. Studies showed first attempt success was higher with RSI $[9,19,20]$. Based on these studies, the hospital intubators require quality improvement projects and should follow standard recommendations during intubation.

The most frequent agent used as a sedative was ketamine. Other studies have used mostly etomidate as a sedative [1], which was not totally available in our setting. Nonetheless, studies had shown ketamine as a safe alternative to etomidate with no side effect of adrenal suppression [21]. 
TABLe 3: First attempt and success rate of intubations at Addis Ababa, Ethiopia.

\begin{tabular}{lccc}
\hline $\begin{array}{l}\text { Intubator } \\
\text { First-year }\end{array}$ & $\begin{array}{c}\text { Number of first attempt } \\
(N=256), n(\%)\end{array}$ & $\begin{array}{c}\text { Successful first attempt from first } \\
\text { attempt, } n(\%)\end{array}$ & $\begin{array}{c}\text { Final number of successful intubations } \\
(N=256), n(\%)\end{array}$ \\
$\begin{array}{l}\text { resident } \\
\text { Second-year } \\
\text { resident }\end{array}$ & $120(46.9)$ & $64 / 120(53.3)$ & $66 / 256(25.8)$ \\
$\begin{array}{l}\text { Third-year } \\
\text { resident }\end{array}$ & $87(34.0)$ & $75 / 87(86.2)$ & $122 / 256(47.7)$ \\
Consultant & $27(10.5)$ & $22 / 27(81.5)$ & $32(12.5)$ \\
Total & $22(8.6)$ & $19 / 22(86.4)$ & $34(13.3)$ \\
\hline
\end{tabular}

TABle 4: Immediate complications of intubations at Addis Ababa, Ethiopia.

\begin{tabular}{lccc}
\hline Complications & RSI $(n=110), n(\%)$ & Non-RSI $(n=146), n(\%)$ & Total $(\%)(N=256)$ \\
\hline$\left(\mathrm{SpO}_{2}\right)<93 \%$, & $13(11.8)$ & $19(13.0)$ & $32(12.5)$ \\
Hypotension & $6(5.5)$ & $19(13.0)$ & $25(9.8)$ \\
Bradycardia<60/min & $3(2.7)$ & $9(6.2)$ & $12(4.7)$ \\
Esophageal intubation & $5(4.5)$ & $2(1.4)$ & $7(2.7)$ \\
Difficult intubation & $4(3.6)$ & $1(0.7)$ & $5(1.9)$ \\
Laryngeal spasm & $1(0.9)$ & $1(0.7)$ & $2(0.8)$ \\
Surgical airway(tracheostomy) & $0(0)$ & $2(1.4)$ & $2(0.8)$ \\
Self-extubation & $1(0.9)$ & $0(0)$ & $1(0.4)$ \\
Vomit appearing in the airway after induction & Not documented & Not documented & Not documented \\
\hline
\end{tabular}

TABLE 5: Type of intubations versus different variables at Addis Ababa, Ethiopia.

\begin{tabular}{|c|c|c|c|c|}
\hline \multirow{2}{*}{\multicolumn{2}{|c|}{ Variables }} & \multicolumn{3}{|c|}{ Medication use/type of intubation } \\
\hline & & RSI $(N=110), n(\%)$ & $\operatorname{SED}(N=129), n(\%)$ & $\operatorname{IOM}(N=16), n(\%)$ \\
\hline \multirow{4}{*}{ Age } & $<16$ & $13(11.8)$ & $16(12.4)$ & $2(12.5)$ \\
\hline & $17-35$ & $45(49.9)$ & $50(38.8)$ & $8(50.0)$ \\
\hline & $36-65$ & $37(33.6)$ & $35(27.1)$ & $5(31.3)$ \\
\hline & $>65$ & $6(5.5)$ & $13(10.1)$ & $1(6.3)$ \\
\hline \multirow{3}{*}{ Sex } & Male & $79(71.8)$ & $100(77.5)$ & $12(75.0)$ \\
\hline & Female & $30(27.3)$ & $27(20.9)$ & $4(25.0)$ \\
\hline & Not documented & $1(0.9)$ & $2(1.6)$ & $0(0)$ \\
\hline \multirow{4}{*}{ First attempt } & First-year resident & $56(50.9)$ & $58(45.0)$ & $5(31.3)$ \\
\hline & Second-year resident & $35(31.8)$ & $41(31.8)$ & $10(62.5)$ \\
\hline & Third-year resident & $5(4.5)$ & $21(16.3)$ & $1(6.3)$ \\
\hline & Consultant & $14(12.7)$ & $8(6.2)$ & $0(0)$ \\
\hline \multirow{2}{*}{ First attempt success } & Successful & $75(68.2)$ & $90(69.8)$ & $14(87.5)$ \\
\hline & Not successful & $34(30.9)$ & $38(29.5)$ & $2(12.5)$ \\
\hline \multirow{5}{*}{ Final intubation } & First-year resident & $34(30.9)$ & $30(23.3)$ & $3(18.8)$ \\
\hline & Second-year resident & $46(41.8)$ & $58(45.0)$ & $12(75.0)$ \\
\hline & Third-year resident & $9(8.2)$ & $24(16.6)$ & $1(6.3)$ \\
\hline & Consultant & $19(17.3)$ & $13(10.1)$ & $0(0)$ \\
\hline & Not documented & $2(1.8)$ & $4(3.1)$ & $0(0)$ \\
\hline \multirow{2}{*}{ Final intubation success } & Successful & $108(98.2)$ & $128(99.2)$ & $16(100)$ \\
\hline & Not successful & $2(1.8)$ & $0(0)$ & $0(0)$ \\
\hline \multirow{2}{*}{ Complication } & Yes & $36(32.7)$ & $50(38.6)$ & $10(62.5)$ \\
\hline & No & $74(67.3)$ & $79(61.2)$ & $6(37.5)$ \\
\hline
\end{tabular}

Index. RSI, rapid sequence intubation; SED, intubation with only sedation; IOM, intubation without medication.

The most commonly used paralytics were succinylcholine, as in other studies [7, 22, 23].

Oxygen desaturation was the most common complication, similar to other studies. This study showed that multiple attempts were associated with complications like other studies [7]. Studies suggested proper preoxygenation and apneic oxygenation with nasal cannula will improve desaturation and also first-pass success rate [24-26].

Above all, the hospital should have intubation protocol on type of intubation, rescue devices, and others to improve the success rate and to decrease intubation-related complications. 


\section{Limitations}

There were several limitations to this study. First and foremost, there was incomplete data for analysis and therefore underlying causes of incomplete data should be explored, with improvements made as needed.

The second limitation was the authors reviewed only the documented intubation sheets, and it was difficult to confirm if all intubations were documented. This could lead to a possible underestimation of overall intubations and other events.
Lastly, the study was not designed to assess the outcome of the intubated patient. Future studies are needed with follow-up of patients to assess mortality and morbidity.

\section{Conclusions}

The intubation first-pass success rate of AaBET Hospital was lower than that of existing studies, but the overall intubation success rate was satisfactory.

\section{Appendix}

\section{A. Annex-1: Intubation Documentation Sheet}

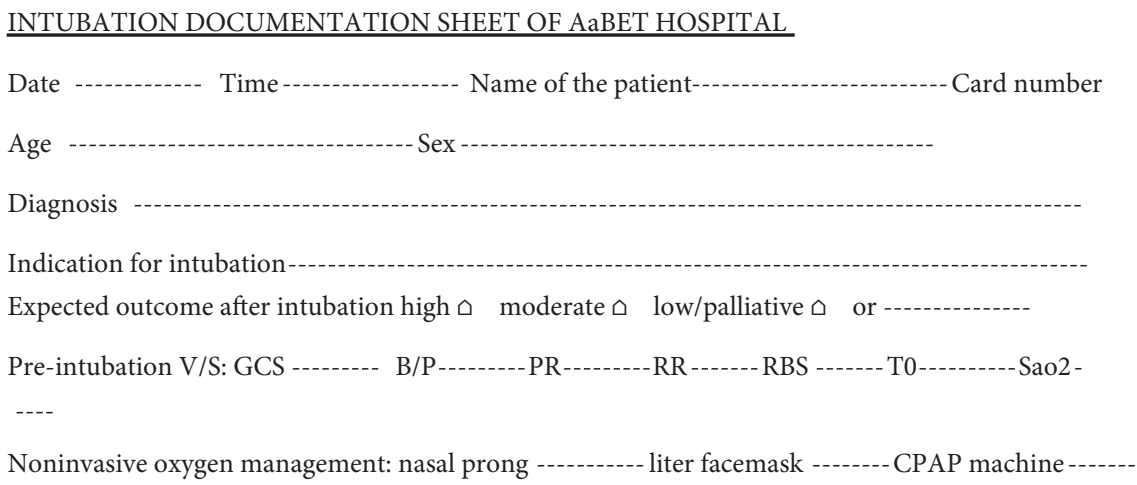

Monitoring during intubation

\begin{tabular}{|l|l|l|l|l|l|l|l|l|l|}
\hline \multirow{2}{*}{ Time } & \multirow{2}{*}{$\mathrm{B} / \mathrm{P}$} & \multirow{2}{*}{$\mathrm{PR}$} & \multirow{2}{*}{$\mathrm{RR}$} & \multirow{2}{*}{$\mathrm{SPO} 2$} & \multirow{2}{*}{$\mathrm{Wt} / \mathrm{Kg}$} & \multicolumn{4}{|c|}{ Medication name and dose } \\
\cline { 6 - 9 } & & & & & & & & & \\
\hline
\end{tabular}

Trail of intubation in \# ----- times by -------- R1--------R2---------By R3 ---------- by consultant

Reason for repeated attempt

ETT size (ID) ------------ Length (depth)

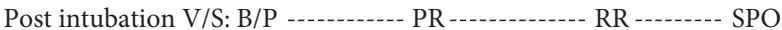
GCS

Is the patient on MV Yes $\square$ No $\square$ if yes type of mode ------------ if no, liter of O2 -----

Intubation by level R1 $\quad$ R2 $\square \quad \mathrm{R} 3 \quad \square \quad$ Consultant $\square \quad$ other responsible person $\square$

Name-1-10-1

Outcome of the procedure: successful $\square \quad$ not successful $\square$

Patient condition: comfortable $\square \quad$ deteriorated $\square \quad$ arrested $\square$

Other notes

Documented by

Signature Time 


\section{B. Annex-2: Questionnaire for the Study}

\begin{tabular}{|c|c|c|}
\hline Number & Variables & $\begin{array}{l}\text { Documentation Yes/No } \\
\text { What is documented }\end{array}$ \\
\hline 1 & Card number & \\
\hline 2 & Date & \\
\hline 3 & Age & \\
\hline 4 & Sex & \\
\hline 5 & Diagnosis & \\
\hline 6 & Indication for intubation & \\
\hline 7 & Pre-intubation BP & \\
\hline 8 & Pre-intubation PR & \\
\hline 9 & Pre-intubation RR & \\
\hline 10 & Pre-intubation SPO2 & \\
\hline 11 & Pre-intubation GCS & \\
\hline 12 & MEDICATION USE & \\
\hline \multirow[t]{2}{*}{13} & If medication $\mathrm{n}$ used & Induction agent \\
\hline & Paralytic agent & \\
\hline 14 & Number of trials & \\
\hline \multirow[t]{4}{*}{15} & Intubation done by & First trial \\
\hline & Second trial & \\
\hline & Third trial & \\
\hline & Fourth trial & \\
\hline
\end{tabular}

\section{Abbreviations}

AaBET Hospital: Addis Ababa Burn Emergency and Trauma Hospital

AEs: $\quad$ Adverse events

ED: $\quad$ Emergency department

EM: $\quad$ Emergency medicine

EPs: $\quad$ Emergency physicians

GCS: Glasgow Coma scale

PR: $\quad$ Pulse rate

SBP: $\quad$ Systolic blood pressure

RSI: $\quad$ Rapid sequence intubation

RR: Respiratory rate

V/s: Vital sign.

\section{Data Availability}

The data used to support the findings of this study are available upon request to the corresponding author.

\section{Disclosure}

There was no funding for this study.

\section{Conflicts of Interest}

The authors declare that there are no conflicts of interest.

\section{Authors' Contributions}

All authors have contributed equally to the conception of the work including the acquisition, analysis or interpretation of data, drafting and revising, and final approval of the version to be published and agreed to be accountable for all aspects of the work.

\section{References}

[1] A. G. M. Stevenson, C. A. Graham, R. Hall, P. Korsah, and A. C. McGuffie, "Tracheal intubation in the emergency department: the Scottish district hospital perspective," Emergency Medicine Journal, vol. 24, no. 6, pp. 394-397, 2007.

[2] F. Toby, A. Nick, H. Kerry et al., "Prospective observational study of the practice of endotracheal intubation in the emergency department of a tertiary hospital in Sydney, Australia," Emergency Medicine Australasia, vol. 24, no. 6, pp. 617-624, 2012. 
[3] C. Reid, L. Chan, and M. Tweeddale, "The who, where, and what of rapid sequence intubation: prospective observational study of emergency RSI outside the operating theatre," Emergency Medicine Journal, vol. 21, no. 3, pp. 296-301, 2004.

[4] L. D. Martin, J. M. Mhyre, A. M. Shanks, K. K. Tremper, and S. Kheterpal, "3,423 emergency tracheal intubations at a University hospital," Anesthesiology, vol. 114, no. 1, pp. 42-48, 2011.

[5] A. E. Bair, M. R. Filbin, R. G. Kulkarni, and R. M. Walls, "The failed intubation attempt in the emergency department: analysis of prevalence, rescue techniques, and personnel," The Journal of Emergency Medicine, vol. 23, no. 2, pp. 131-140, 2002.

[6] Y. Goto, H. Watase, C. A. Brown et al., "Emergency airway management by resident physicians in Japan: an analysis of multicentre prospective observational study," Acute Medicine \& Surgery, vol. 1, no. 4, pp. 214-221, 2014.

[7] J. C. Sakles, S. Chiu, J. Mosier, C. Walker, and U. Stolz, "The importance of first pass success when performing orotracheal intubation in the emergency department," Academic Emergency Medicine, vol. 20, no. 1, pp. 71-78, 2013.

[8] K. Hasegawa, K. Shigemitsu, Y. Hagiwara et al., "Association between repeated intubation attempts and adverse events in emergency departments: an analysis of a multicenter prospective observational study," Annals of Emergency Medicine, vol. 60, no. 6, pp. 749-754, 2012.

[9] B. Ligier, T. G. Buchman, M. J. Breslow et al., "The role of anesthetic induction agents and neuromuscular blockade in the endotracheal intubation of trauma victims," Surg Gynecol Obstet, vol. 173, pp. 477-481, 1991.

[10] J. Benger and S. Hopkinson, "Rapid sequence induction of anaesthesia in UK emergency departments: a national census," Emergency Medicine Journal, vol. 28, no. 3, pp. 217-220, 2011.

[11] M. J. Sagarin, E. D. Barton, Y.-M. Chng, and R. M. Walls, "Airway management by US and Canadian emergency medicine residents: a multicenter analysis of more than 6,000 endotracheal intubation attempts," Annals of Emergency Medicine, vol. 46, no. 4, pp. 328-336, 2005.

[12] R. M. Walls, C. A. Brown, and D. J. Pallin, "Emergency airway management: a multi-center report of 8937 emergency department intubations," The Journal of Emergency Medicine, vol. 41, no. 4, pp. 347-354, 2011.

[13] E. Bair, Y. T. Fong, and K. K. Ho, "Emergency airway management-experience of a tertiary hospital in South-East Asia," Resuscitation, vol. 61, no. 3, pp. 349-355, 2004.

[14] M. D. April, A. Arana, and D. J. Pallin, "Emergency department intubation success with succinylcholine versus rocuronium: a national emergency airway registry study," Annals of Emergency Medicine, vol. 72, no. 6, pp. 645-653, 2018.

[15] M. S. Baek, M. J. Han, and J. W. Hu, "Video laryngoscopy versus direct laryngoscopy for first-attempt tracheal intubation in the general ward," Ann. Intensive Care, vol. 8, no. 83, 2018.

[16] S. Nakao, A. Kimura, Y. Hagiwara et al., "Trauma airway management in emergency departments: a multicentre, prospective, observational study in Japan," BMJ Open, vol. 5, Article ID e006623, 2015.

[17] M. C. Dunham, R. D. Barraco, D. E. Clark et al., "Guidelines for emergency tracheal intubation immediately after traumatic injury," The Journal of Trauma: Injury, Infection, and Critical Care, vol. 55, no. 1, pp. 162-179, 2003.
[18] American College of Surgeons COT, Advanced Trauma Life Support for Doctors, Student Course Manual, American College of Surgeons COT, Chicago, IL, USA, 8th edition, 2008.

[19] M. Okubo, K. Gibo, Y. Hagiwara et al., "The effectiveness of rapid sequence intubation (RSI) versus non-RSI in emergency department: an analysis of multicenter prospective observational study," International Journal of Emergency Medicine, vol. 10, no. 1, 2017.

[20] E. Vijayakumar, H. Bosscher, F. F. Renzi, S. Baker, and S. O. Heard, "The use of neuromuscular blocking agents in the emergency department to facilitate tracheal intubation in the trauma patient: help or hindrance?" Journal of Critical Care, vol. 13, no. 1, pp. 1-6, 1998.

[21] A. Pai and M. Heining, "Ketamine," Continuing Education in Anaesthesia Critical Care \& Pain, vol. 7, no. 2, pp. 59-63, 2007.

[22] S. M. Fathil, S. N. Mohd. Mahdi, Z. Che’Man, A. Hassan, Z. Ahmad, and A. K. Ismail, "A prospective study of tracheal intubation in an academic emergency department in Malaysia," International Journal of Emergency Medicine, vol. 3, no. 4, pp. 233-237, 2010.

[23] A. Y. B. Tam and F. L. Lau, "A prospective study of tracheal intubation in an emergency department in Hong Kong," European Journal of Emergency Medicine, vol. 8, no. 4, pp. 305-310, 2001.

[24] D. Scott, M. D. Weingart, and R. M. Levitan, "Preoxygenation and prevention of desaturation during emergency airway management," Ann Emerg Med, vol. 59, pp. 165-175, 2012.

[25] J. Gleason, B. Christian, and E. Barton, "Nasal cannula apneic oxygenation prevents desaturation during endotracheal intubation: an integrative literature review," Western Journal of Emergency Medicine, vol. 19, no. 2, pp. 403-411, 2018 Mar.

[26] D. P. Davis, J. Lemieux, J. Serra et al., "Preoxygenation Reduces Desaturation Events and Improves Intubation Success," Air Medical Journal, vol. 34, no. 2, pp. 82-85, 2015. 